\title{
Lump Circuit Modeling and Matching Consideration on Acoustical Transmitters for Underwater Application
}

\author{
Yeong-Chin Chen \\ Department of Electronics Engineering and Computer Science, Tong-Fang Institute of Technology, 110 Tung-Fang \\ Road, Hunei Shiang, Kao-Shiung, Taiwan 829, Republic of China, ycchen@mail.tf.edu.tw \\ Sean Wu \\ Department of Electronics Engineering and Computer Science, Tong-Fang Institute of Technology, 110 Tung-Fang \\ Road, Hunei Shiang, Kao-Shiung, Taiwan 829, Republic of China \\ Cheng-Che Tsai \\ Department of Electronics Engineering and Computer Science, Tong-Fang Institute of Technology, 110 Tung-Fang \\ Road, Hunei Shiang, Kao-Shiung, Taiwan 829, Republic of China
}

Follow this and additional works at: https://jmstt.ntou.edu.tw/journal

Part of the Electrical and Computer Engineering Commons

\section{Recommended Citation}

Chen, Yeong-Chin; Wu, Sean; and Tsai, Cheng-Che (2004) "Lump Circuit Modeling and Matching Consideration on Acoustical Transmitters for Underwater Application," Journal of Marine Science and Technology. Vol. 12: Iss. 3, Article 3.

DOI: $10.51400 / 2709-6998.2233$

Available at: https://jmstt.ntou.edu.tw/journal/vol12/iss3/3

This Research Article is brought to you for free and open access by Journal of Marine Science and Technology. It has been accepted for inclusion in Journal of Marine Science and Technology by an authorized editor of Journal of Marine Science and Technology. 


\section{Lump Circuit Modeling and Matching Consideration on Acoustical Transmitters}

for Underwater Application

\section{Acknowledgements}

This research was supported by the National Science Council of Republic of China, under grant No. NSC93-2216-E-272-003. 


\title{
LUMP CIRCUIT MODELING AND MATCHING CONSIDERATION ON ACOUSTICAL TRANSMITTERS FOR UNDERWATER APPLICATION
}

\author{
Yeong-Chin Chen*, Sean Wu, and Cheng-Che Tsai
}

Key words: lump circuit, acoustical transmitter, equivalent circuit, impedance matching, underwater application.

\section{ABSTRACT}

In underwater environment the acoustical wave can transmit a long ranges away from the transmitter than the electromagnetic wave does. So far, the piezoelectric ceramic is still the best candidate as acoustical telemetry transmitters in underwater applications. The impedance matching on the interface between electro-acoustical transducer and electrical transmitter has been the most important subject to confirm the high transmitting efficiency. In this research, a lumped equivalent circuit of electro-acoustic transducer is proposed. Then, the network theorem is implemented to design a high power transformer for impedance matching, and to improve the electro-acoustic efficiency of the transducer. In the developing procedure, the transducer's impedance is measured and the circuit element of equivalent circuit is deduced from the measured data to correlated the simulated values of the equivalent circuit. Then the matching transformer is developed to meet the specifications of impedance matching and high power operation. The equivalent circuit of the electroacoustic transducer with matching transformer was developed and simulated using Hp-Vee program. The simulated results quite agree with the measured results. This approach really develops an effective method for impedance matching design and reduced the time for trial and error.

\section{INTRODUCTION}

Underwater acoustical transducer is utilized as the physical element for sound wave transmitting and receiving in sonar system. By transmitting a sound wave from the transducers, the surface or underwater objects ranging several miles away from the sonar transducers can be located by detected the reflected sound wave from the objects itself. For the high power application,

Paper Submitted 01/07/04, Accepted 05/10/04. Author for Correspondence: Yeong-Chin Chen. E-mail: ycchen@mail.tf.edu.tw.

*Department of Electronics Engineering and Computer Science, Tong-Fang Institute of Technology, 110 Tung-Fang Road, Hunei Shiang, Kao-Shiung, Taiwan 829, Republic of China the transducer is typical structured like a "Tonpilz" to produce reinforced mechanical motion of high-power sound generation. Detailed discussion of these longitudinal vibrators may be found in literatures $[5,8,10,12$, 13]. However, Tonpilz transducer possesses characteristics of high dielectric resistance and capacitance and is hard to be driven by the electrical amplifier. A selfcoupled transformer is implemented to link the electrical driving system and the transducer to improve the transmitting efficiency.

An equivalent circuit based on lumped constant mode [4] is proposed as an analogy to electromechanical characteristics of the Tonpilz transducer. Then, the circuit elements were deduced from the impedance properties of the transducer. A PC-based automatic testing system is built to measure the transducer's properties.

Since the testing program is programmed by $\mathrm{Hp}$ Vee [6] software, the matching transformer is also designed and simulated using the same software. The impedance properties of the matched transducer could be obtained from the testing system and as a reference to the transformer design.

\section{LUMPED CIRCUIT MODELING}

A cross-section of the Tonpilz transducer is shown in Fig. 1, along with the simplest spring-mass [1] idealization. The device consists of a stack of eight PZT4 ring transducer elements electrically connected in parallel, a steel tail mass, a flared aluminum head mass and a steel compression bolt [15]. The sphere volume in the spring-mass model indicates relative lumped mass of the tail $M_{T}^{\prime}$ and head $M_{H}^{\prime}$, for the device. The mechanical compliance and vibration loss of ceramic segments are indicated by $C_{m}$ and $R_{m}$.

If the transducer is vibrating longitudinally in the fundamental mode, there exists a node, $X_{n}$, where the vibrating displacement is zero at all times. If friction loss and other mechanical losses are ignored, according 
to the "conservation of energy" theorem, the node can be derived by [2]

$$
\begin{aligned}
& M_{T}^{\prime} X_{n}^{2}=M_{H}^{\prime}\left(1-X_{n}\right)^{2}, \\
& M_{T}^{\prime}=M_{T}+M_{C} X_{n}, M_{H}^{\prime}=M_{H}+M_{C}\left(1-X_{n}\right),
\end{aligned}
$$

where $M_{H}$ is the head mass, $M_{c}$ is the mass of ceramic segments, and $M_{T}$ is the tail mass.

The equivalent network of the Tonpiltz transducer is described in Fig. 2, where the electrical system is composed of the clamped capacitance $\left(C_{0}\right)$ and the dielectric resistance $\left(R_{0}\right)$ the mechanical system is composed of the spring-mass model described in Fig. 1, and $N c$ (Newton/voltage) are the electromechanical transformation ratio between the electrical and mechanical systems.

In underwater applications, the Tonpiltz transducer is encapsulated in polyurethane to render it waterresistant where it acts as a projector in the water medium. The effective radiating impedance $\left(Z_{w}\right)$ of a baffled piston in water can be expressed by $[9,16]$

$$
Z_{W}=R_{W}+j X_{W}=\rho c A_{H} R_{1}(2 K a)+j \rho c A_{H} X_{1}(2 K a),
$$

where $\rho$ is density of water, $c$ is sound velocity in water, $A_{H}$ is the radiating surface area, $a$ is radius of radiating surface, $\lambda$ is wavelength of sound in water, and $K=\frac{2 \pi}{\lambda}$ is phase velocity. The functions of $X_{1}(2 K a)$ and $R_{1}$ $(2 \mathrm{Ka})$ are represented by

$$
\begin{aligned}
& R_{1}(X)=1-\frac{2 J_{1}(X)}{X}=\frac{X^{2}}{2^{2} 2 !}-\frac{X^{4}}{2^{4} 2 ! 3 !}+\cdots \\
& X_{1}(X)=\frac{4}{\pi}\left[\frac{X}{3}-\frac{(X)^{3}}{3^{3} \cdot 5}+\frac{(X)^{5}}{3^{2} 5^{2} \cdot 7}-\cdots\right]
\end{aligned}
$$
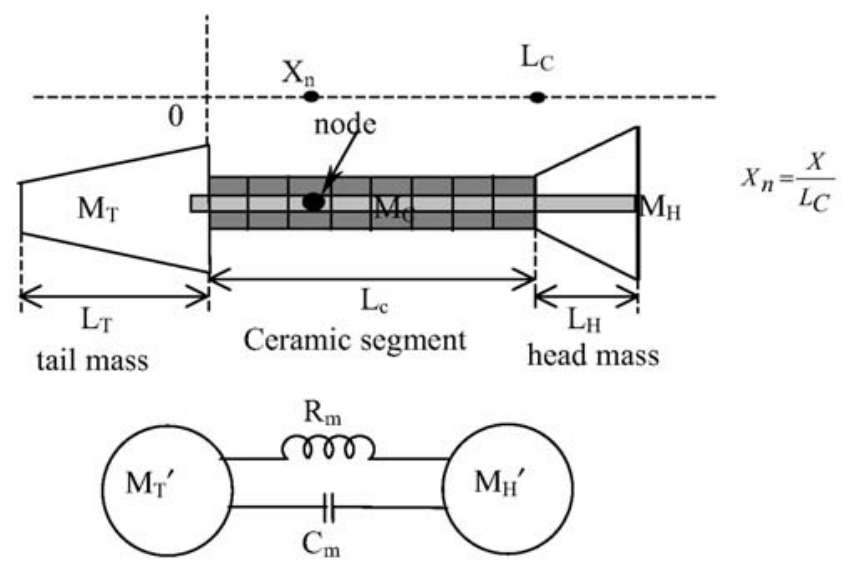

Fig. 1. Tonpiltz transducer cross-section and simple spring-mass model.
In some cases, the radiating surface is a square. Considering the boundary condition, eq. (3) is modified as

$$
Z_{W}=\alpha R_{W}+j \beta X_{W}=R_{W}^{\prime}+j X_{W}^{\prime},
$$

where the modified factors $\alpha$ and $\beta$ are obtained from several experimental procedures. If the transducer is working under water, the radiating load should be included in the equivalent circuit shown in Fig. 3, where

$$
R_{r}=R_{W}, M_{W}=\frac{X_{W}^{\prime}}{W} .
$$

Reducing the mechanical portion of Fig. 3, the equivalent circuit of the transducer is described by Fig. 4 , where the electromechanical transformation ratio is given as

$$
N_{C}=\sqrt{C_{M} / C_{m}}
$$

\section{IMPEDANCE MATCHING}

The input electrical admittance of the transducer can be written as

$$
Y_{I N}=Y_{E}+Y_{M}=\frac{1}{R_{0}}+j \omega C_{0}+\frac{1}{R_{M}+j\left(\omega L_{M}-\frac{1}{\omega C_{M}}\right)},
$$

where $Y_{E}$ is the electrical admittance, $Y_{M}$ is mechanical admittance, $R_{0}$ is the dielectric resistance, $C_{0}$ is the clamped capacitance, $R_{M}$ is the motional resistance, $L_{M}$ is the motional inductance, $C_{M}$ is the motional capacitance.

When the transducer is operating on its mechanical resonance frequency, the admittance $Y_{I N}$ becomes $\frac{1}{R_{0}}+j \omega C_{0}+\frac{1}{R_{M}}$. A self-coupled transformer with the secondary inductance value $L_{T}$ shown in the dark area of Fig. 4 is developed to cancel out the clamped capacitance $C_{0}$ and make the phase angle $(\theta)$ of the transducer's

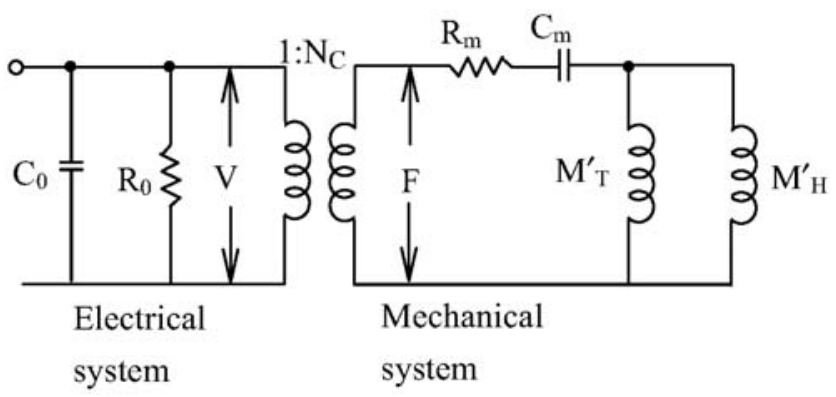

Fig. 2. Equivalent circuit of tonpiltz transducer working in air. 
impedance zero [3]. By tuning the turns ratio of the transformer, the impedance value $\left(\left|Z_{I N}\right|\right)$ is also modified to the specific value so as to improve the efficiency of the electric driving system. The electrical admittance of the resonating transducer after tuning becomes

$$
\begin{aligned}
& \left(Z_{I N}\right)^{-1}=Y_{I N}=\left[j \omega_{S} C_{0}+\frac{1}{j \omega_{S} L_{T}}\right. \\
& \left.+\frac{1}{R_{M}+j\left(\omega_{S} L_{M}-\frac{1}{\omega_{S} C_{M}}\right)}\right]\left(\frac{n_{1}+n_{2}}{n_{1}}\right) \\
& =\frac{1}{R_{M}}\left(\frac{n_{1}+n_{2}}{n_{1}}\right) .
\end{aligned}
$$

The primary inductance $\left(L_{1}\right)$ and the secondary inductance $\left(L_{T}\right)$ has the relation given by

$$
L_{T}=\left[\frac{n_{1}+n_{2}}{n_{1}}\right]^{2} L_{1}
$$

where $n_{1}$ and $n_{2}$ are winding turns of $L_{1}$ and $L_{2}$ respectively. The secondary inductance $L_{T}$ is derived from

$$
L_{T}=\frac{1}{C_{0} \omega_{S}^{2}} .
$$

According to the networking theorem, the voltage and current relations of input $\left(V_{1}, I_{1}\right)$ an

d output $\left(V_{2}, I_{2}\right)$ in Figs. 3 can be given by

$$
\begin{aligned}
{\left[\begin{array}{l}
V_{1} \\
I_{1}
\end{array}\right]=} & {\left[\begin{array}{cc}
\frac{n_{1}}{n_{1}+n_{2}} & 0 \\
0 & \frac{n_{1}+n_{2}}{n_{1}}
\end{array}\right]\left[\begin{array}{cc}
1 & 0 \\
\frac{1}{j \omega L_{T}}+j \omega C_{0}+\frac{1}{R_{0}} & 1
\end{array}\right] } \\
& {\left[\begin{array}{cc}
\frac{1}{N_{C}} & 0 \\
0 & N_{C}
\end{array}\right]\left[\begin{array}{cc}
1 & \frac{1}{j \omega C_{m}}+R_{m} \\
0 & 1
\end{array}\right] }
\end{aligned}
$$$$
\left[\begin{array}{cc}
1 & 0 \\
\frac{1}{j \omega M_{T}^{\prime}} & 1
\end{array}\right]
$$$$
\left[\begin{array}{cc}
1 & 0 \\
\frac{1}{j \omega\left(M_{H}^{\prime}+M_{w}\right)+R_{r}} & 1
\end{array}\right]
$$$$
\left[\begin{array}{c}
V_{2} \\
I_{2}=0
\end{array}\right] \text {. }
$$

From eq. (13a), the input impedance of transducer is

$$
Z_{I N}=\frac{V_{1}}{I_{1}}
$$

\section{DESIGN PROCEDURE}

For a specific underwater high power electroacoustical transducer, the maximum operating power $\left(P_{\max }\right)$ is $800 \mathrm{~W}$, impedance value $\left(Z_{I N}\right)$ at resonant frequency $(3.3 \mathrm{kHz})$ is $145 \Omega$ and the phase $\operatorname{angle}(\theta)$ is $\pm 10^{\circ}$, a practical design flow chart is shown in Fig. 5 and the detailed procedure is described in the following:

\section{Transducer measurement and circuit element evalua- tion}

Before the matching transformer is applied on it, the transducer is dipped in the water tank and measured by HP 4194A impedance/gain phase analyzer. The transducer's properties are measured and listed as follow: the electrical capacitance of transducer at DC is $C_{T}=$ $8.747 \mathrm{nF}$, the dielectric loss of piezoelectric ceramic is $\tan \delta=0.2 \%$, the frequency of motional (series) reso-

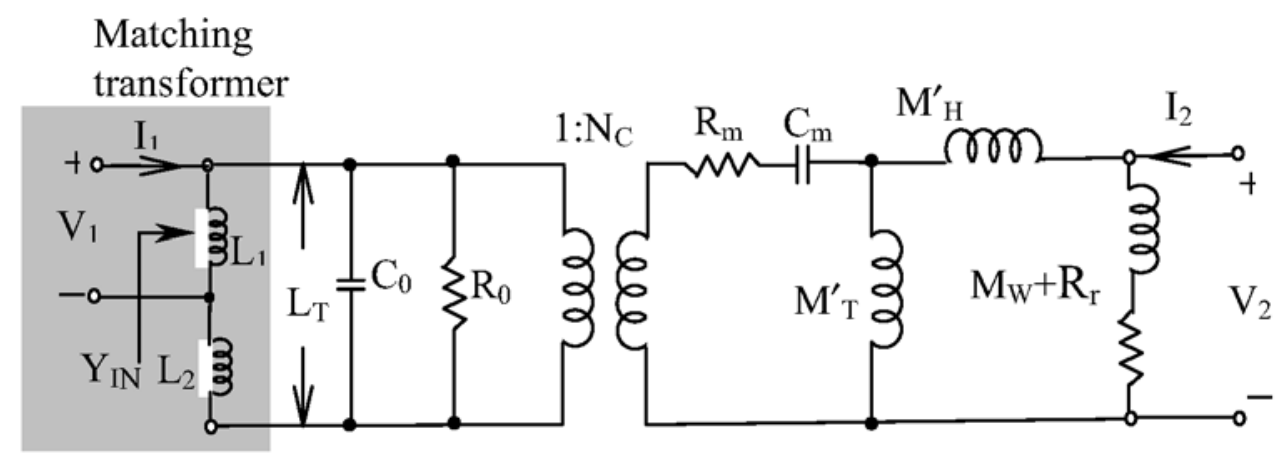

Fig. 3. Equivalent circuit of tonpiltz transducer working in water. 
nance is $f_{S}=3.3 \mathrm{kHz}$, the parallel resonance frequency is $f_{P}=3.7 \mathrm{kHz}$, the electrical conductance at motional resonance is $G_{S}=1.543 \mathrm{E}-4 \Omega^{-1}$, the electrical susceptance at motional resonance is $B_{S}=1.085 \mathrm{E}-4 S$, the electromechanical coupling factor is $K_{\text {eff }}=0.313$.

From the measured data, the elements value of the transducer's equivalent circuit shown in Fig. 4 is derived [7, 17], where $C_{0}=7889 \mathrm{pF}, R_{M}=11.1 \mathrm{k} \Omega, C_{M}=$ $858 \mathrm{pF}, L_{M}=2.71 \mathrm{H}, R_{0}=6.3 \mathrm{M} \Omega$.

\section{Inductance and turns ratio evaluation}

To improve the transmitting efficiency, the matched transducer's phase angle of impedance is tuned to zero at resonance frequency, the secondary inductance of the transformer is obtained by

$$
L_{T}=\frac{1}{\omega_{S}^{2} C_{0}}=294.7 \mathrm{mH}
$$

Taking $Z_{I N}=145 \Omega$, the turns ratio is calculated by

$$
\frac{n_{1}}{n_{1}+n_{2}}=\sqrt{\frac{Z_{I N}}{R_{M}}}=\sqrt{\frac{145}{11.1 \times 10^{3}}}=\frac{1}{8.75} .
$$

The primary inductance of the transducer is

$$
L_{1}=L_{T} \times\left(\frac{n_{1}}{n_{1}+n_{2}}\right)^{2}=3.85 \mathrm{mH}
$$

\section{THE WINDING DESIGN AND CORE DETERMINATION}

\section{Wire size evaluation}

The maximum primary-winding current is derived from the maximum operation power, $800 \mathrm{~W}$, and the impedance,

$$
I_{1}=\sqrt{\frac{P_{\max }}{Z_{I N}}}=\sqrt{\frac{800}{145}}=2.349 \mathrm{Amp}
$$

And, the maximum secondary-winding current is

$$
I_{2}=I_{1} \times \frac{n_{1}}{n_{1}+n_{2}}=2.349 A m p \times \frac{1}{8.75}=0.268 A m p
$$

Assuming the safety current density $D$ in circular mil per Ampere is 500 c.m./A, the minimum wire size for the primary-winding is $500 \times 2.349=1175$ c.m., and for the secondary is $500 \times 0.268=134$ c.m.. So AWG19 wire $(1,290$ c.m.) is used for the primary, and AWG28 wire (159 c.m.) is used for the secondary.

\section{Core determination}

If temperature is the principal limitation for the high power transformer, this product of $A_{e}$ and $A_{w}$ must meet the specification

$$
A_{e} A_{w}=\frac{2.75 \times P_{\text {out }} \times D}{f B_{\text {max }} k_{p}}\left[\text { in }^{4}\right],
$$

where $A_{w}$ is window area, $A_{e}$ is the cross-sectional area of the core flux path, $P_{\text {out }}$ is output power, $f$ is frequency of the applied voltage, $k_{p}$ is winding space factor.

According to the deduction result, a NationalArnold [14] Silectron tape-wound $C$ core is chosen for the transformer design. If the primary winding space factor $\left(k_{p}\right)$ is 0.14 , which is more less than 0.5 . The minimum $A_{e} A_{w}$ product will be

$$
A_{e} \times\left. A_{w}\right|_{\min }=\frac{2.75 \times 800 \times 500}{3.3 \times 10^{3} \times 14,000 \times 0.14}=0.17 \mathrm{in}^{4}
$$

Thus the available National-Arnold (type CZ-7-J) tape-wound $C$ core with $A_{e}=0.703 \mathrm{in}^{2}$ and $A_{w}=1.75 \mathrm{in}^{2}$ $\left(A_{e} \times A_{w}=1.23 \mathrm{in}^{4}\right)$ is the candidate for this transformer

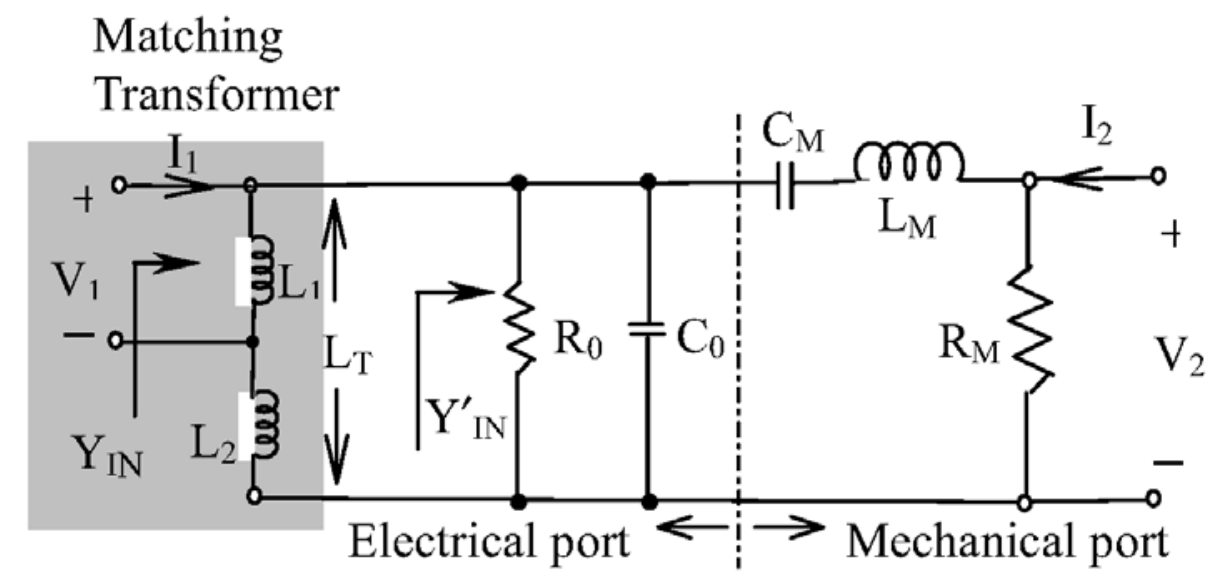

Fig. 4. Simplified equivalent circuit of tonpiltz transducer with matching transformer. 
design.

\section{Winding-turns evaluation}

The primary turns will be [11]

$N_{P}=n_{1}=\frac{V_{P} \times 10^{8}}{4.44 f B_{\max } A_{e}\left(c m^{2}\right)}$

$$
\begin{aligned}
& =\frac{(145 \times 2.349) \times 10^{8}}{4.44 \times 3.3 \times 10^{3} \times 14,000 \times 0.703 \times(2.54)^{2}} \\
& =37 \text { Turns }
\end{aligned}
$$

The secondary turns is

$N_{S}=n_{2}=n_{1} \times\left(\frac{8.75}{1}-1\right)=287$ Turns
Input

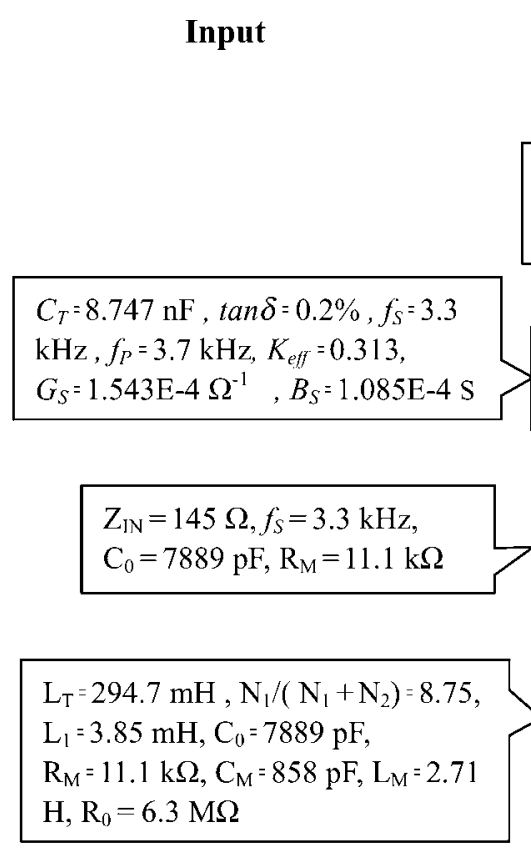

Safty current density $\mathrm{D}=500$ c.m. $/ \mathrm{A}, \mathrm{P}_{\text {in }}=800 \mathrm{~W}, \mathrm{Z}_{\text {in }}=145 \Omega$

$k_{p}=0.14, \mathrm{f}_{\mathrm{s}}=3.3 \mathrm{kHz}, \mathrm{D}=500$ c.m. $/ \mathrm{A}, \mathrm{B}_{\max }=14000, \mathrm{P}_{\mathrm{in}}=800 \mathrm{~W}$

$\mathrm{Z}_{\mathrm{IN}}=145 \Omega, f_{\mathrm{S}}=3.3 \mathrm{kHz}, \mathrm{I}_{\mathrm{P}}=2.349$ Amp, $B_{\max }=14000, A_{e}=0.703 \mathrm{in}^{2}$

$N_{P}=37$ Turns, $A_{e}=0.703 \mathrm{in}^{2}$, $\mathrm{L}_{1}=3.85 \mathrm{mH}$

Dimension of core, $\ell_{g}=0.228$ $\mathrm{mm}, \mathrm{A}_{\mathrm{e}}=0.703 \mathrm{in}^{2}$,
Design Flow

\section{Output}

$C_{T}=8.747 \mathrm{nF}, \tan \delta=0.2 \%, f_{S}=3.3$

$\mathrm{kHz}, f_{P}=3.7 \mathrm{kHz}, K_{e f f}=0.313$, $G_{S}=1.543 \mathrm{E}-4 \Omega^{-1}, B_{S}=1.085 \mathrm{E}-4 \mathrm{~S}$ (without matching)

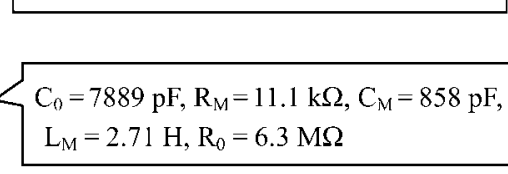

Circuit element evaluation

\section{$\mathrm{L}_{\mathrm{M}}=2.71 \mathrm{H}, \mathrm{R}_{0}=6.3 \mathrm{M} \Omega$}

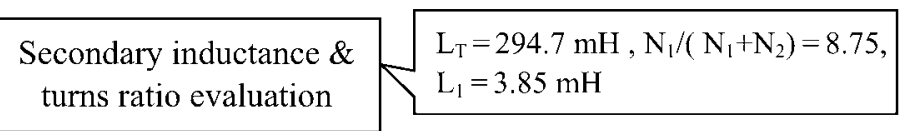

Wire size determination

$\mathrm{I}_{\mathrm{P}}=2.349$ Amp, pimarywire $=1175$ c.m. (AWG19), $I_{\mathrm{S}}=0.268 \mathrm{Amp}$, secondary wire $=134$ c.m. (AWG28)

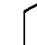

size determination

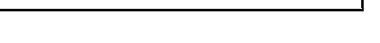

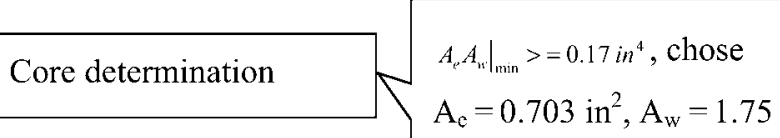

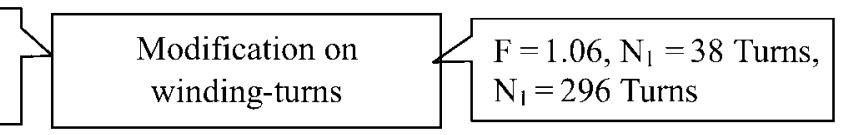

Air gap for inductance design $\ell_{g}=0.228 \mathrm{~mm}$

Measurement (with matching) \& simulation

Measured data \& Simulated data

\section{End}

Fig. 5. Matching transformer design flow. 


\section{Air gap determination for specified inductance}

The air-gap for primary inductance $L_{1}=3.42 \times$ $10^{-3}$ will be [11]

$$
\begin{aligned}
\ell_{g} & \cong \frac{0.4 \pi N_{P}^{2} A_{e}\left(\mathrm{~cm}^{2}\right) \times 10^{-8}}{L_{1}} \\
& =\frac{0.4 \pi \times N_{P}^{2} \times 0.703 \times(2.54)^{2} \times 10^{-8}}{3.42 \times 10^{-3}} \\
& =0.0228 \mathrm{~cm} \cong 0.228 \mathrm{~mm}
\end{aligned}
$$

\section{Modification of winding-turns} obtain

The dimension of $C$ core is shown in Fig. 6, that we

$$
\ell_{i}=2(G+F+2 E)=8 \text { inch }=20.32 \mathrm{~cm} .
$$

Core CZ-7-J showed that $u_{i} \geq 6,000$ (Linear) at $3.3 \mathrm{kHz}$, thus

$$
\frac{\ell_{i}}{\mu_{i}} \leq 3.4 \times 10^{-3} \mathrm{~cm}, \ell_{g}+\frac{\ell_{i}}{u_{i}} \approx \ell_{g}=0.228 \mathrm{~mm}
$$

The ringing flux effect [17] $F$ is determined from the data deduced above and gives

$$
\begin{aligned}
F & =\left(1+\frac{\ell_{g}}{\sqrt{A_{e}}} \ell_{n} \frac{2 G}{\ell_{g}}\right)=1 \\
& +\frac{0.0228}{\sqrt{0.703 \times(2.54)^{2}}} \ell_{n} \frac{2 \times 1.75 \times 2.54}{0.0228} \\
& =1+0.01071 \times \ell_{n} 389.91=1.0639
\end{aligned}
$$

Since a winding turns possess an inductor and could be calculated as [11]

$$
L^{\prime}=\frac{N \phi}{I}=\frac{N B A_{e}}{I}=F L=\frac{F \times 0.4 \pi N^{2} A_{e} \times 10^{-8}}{\ell_{g}+\frac{\ell_{i}}{u_{i}}} H,
$$

$F$ is proportional to the square of turns, the winding turns is modified as

$$
\begin{aligned}
& N_{1}=37 / \sqrt{1.0693}=36 \text { Turns and } \\
& N_{2}=287 / \sqrt{1.0693}=278 .
\end{aligned}
$$

\section{RESULTS AND DISCUSSION}

Figures 7 and 8 show the impedance value and phase angle of the transducer, before and after impedance are matched. Before impedance tuning, the impedance is $5.3 \mathrm{k} \Omega @ 3.3 \mathrm{kHz}$, and the phase angle is $-61^{\circ} @$ $3.3 \mathrm{kHz}$. After impedance matching, the transducer shows that the impedance is $143 \Omega @ 3.3 \mathrm{kHz}$, the phase angle is $-3^{\circ} @ 3.3 \mathrm{kHz}$, which meet the specification (impedance in 5\% deviation, phase angle between $-5^{\circ} \sim$ $-5^{\circ}$ ). In Fig. 8, the simulated data (dot line) agrees the measured data (dotted line) very well. The impedance curve shows a peak at $2.9 \mathrm{kHz}$ which is attributed to the resonance phenomena between the secondary inductance of the matching transformer $\left(L_{T}\right)$ and the clamped capacitance $\left(C_{0}\right)$.

The power handling capability of the matching transformer is verified by measuring the primary inductance $\left(L_{1}\right)$ and quality factor $\left(Q_{1}\right)$ depended on varies current level as the secondary port of the transformer is circuitry opened. As shown in table 1, the deviation of primary inductance and quality factor is less than $1 \%$ as the current level varying from $0.5 \mathrm{~A}$ to $3 \mathrm{~A}$. The

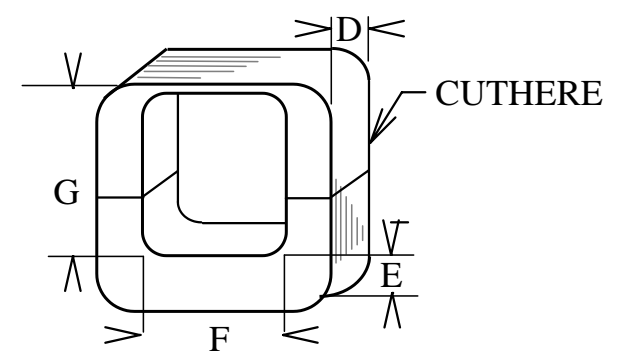
D: 1.125 in $E: 0.625$ in
$\mathrm{F}: 1$ in
G: 1.75 in $\quad \mathrm{Ae}(=\mathrm{D} \times \mathrm{E}): 0.703 \mathrm{in}^{2} \quad \mathrm{Aw}(=\mathrm{G} \times \mathrm{F}): 1.75 \mathrm{in}^{2}$

Fig. 6. Dimension of $\mathrm{C}$ core.

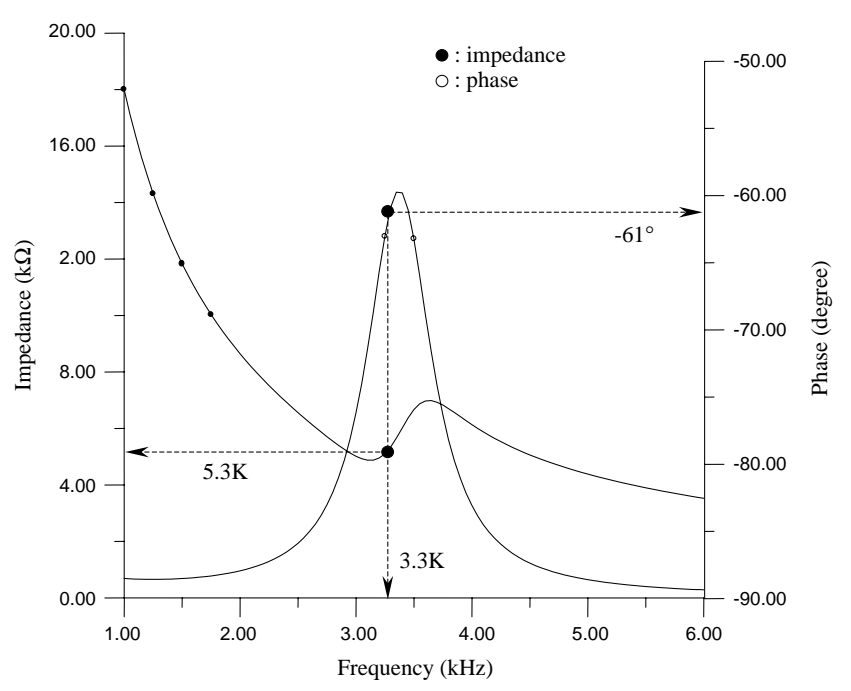

Fig. 7. Impedance of transducer without matching. 


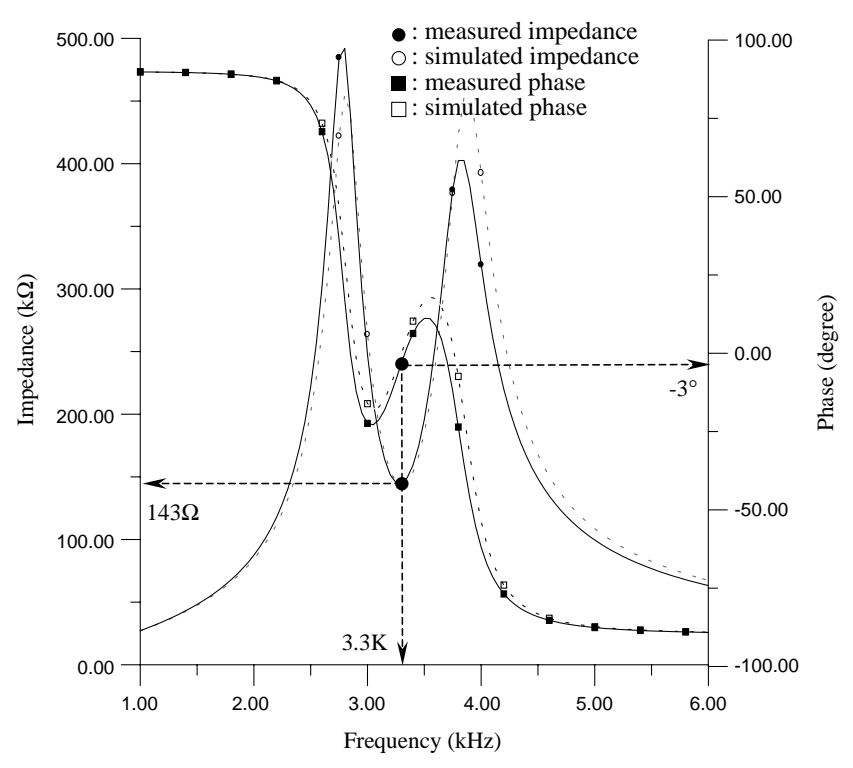

Fig. 8. Impedance of transducer with matching.

secondary inductance $\left(L_{T}\right)$ and quality factor $\left(Q_{T}\right)$ is also measured in the same way as those of the primary with LCR meter analyzer (HP 4284A) by varying the secondary current from $0.05 \mathrm{~A}$ to $0.3 \mathrm{~A}$.

The contribution of this research is to propose an impedance measurement of electro-acoustical transducers and to derive the parameters of the lumped-element equivalent circuit of the transducer. Based on the lumped equivalent circuit, the matching theorem is applied to design the transformer and the transducer's performance using Hp-Vee software program. The power capability for the transformer design is also considered in this research. The simulation results really approve the effectiveness of this lumped-circuit model of the transducer. The measurement and simulation are processed in the same software environment really reduced the time for trial and errors.

\section{ACKNOWLEDGEMENT}

This research was supported by the National Science Council of Republic of China, under grant No. NSC93-2216-E-272-003.

\section{REFERENCES}

1. Baumeister, T., Mechanical Engineers' Hand Book, 6th Ed., McGraw-Hill, New York, pp. 95-108 (1958).

2. Chen, Y.C., Wu, L., Chang, K.K., and Huang, C.L., "Analysis and Simulation of Stacked-Segment Electro- mechanical Transducers with Partial Electrical Excitation by PSPICE,' Japan. J. Appl. Phys., Vol. 36, Part 1, No. 10, pp. 6550-6557 (1997).

3. Chen, Y.C., Wu, L., Chang, K.K., and Huang, C.L., "PSPICE Simulation of Tonpiltz Transducer with Different Metal Material Loaded on Both Ends," Ferroelectrics, Vol. 220, pp. 31-54 (1999).

4. Chen, Y.C. and Wu, S., "A Design Approach of Tonpiltz Transducer," Japan. J. Appl. Phys., Vol. 41, Part 1, No. 6A, pp. 3866-3877 (2002).

5. Gough, P.T. and Knight, J.S., "Wide Bandwidth, Constant Beamwidth Acoustic Project: A Simplified Design Procedure," IEEE Ultrasonics Symposium, pp. 341-345 (1992).

6. Helsel, R., Visual Programming with HP VEE, Third Edition, Prentice-Hall, Inc., New Jersey (1998).

7. Hughes, W.J., Encyclopedia of Applied Physics, Vol. 2, Transducer, Underwater Acoustics Chapter, Wiley-VCH Verlag GmbH, New York, USA (1998).

8. Inoue, T., Sasak, T., Miyama, T., Sugiuchi, K., and Takahashi, S., "Equivalent Circuit Analysis for Tonpiltz Piezoelectric Transducer," Trans. IEICE, Vol. E70, No. 10, pp. 909-917 (1987).

9. Kinsler, L.E., Frey, A.R., Coppens, A.B., and Sanders, J.V., Fundamentals of Acoustics, 3rd Ed., Jon Wiley and Sonics, Inc., New York, pp. 163-196 (1982).

10. Krimholtz, R., Leedom, D.A., and Matthaei, G.L., "New Equivalent Circuits for Elementary Piezoelectric Transducers," Electro. Lett., Vol. 6, No. 13, pp. 398-399 (1970).

11. Lee, R., Wilson, L., Carter, C.E., Electronic Transformers and Circuits, 3rd Ed., John Wiley and Sons, Inc., New York (1988).

12. Martin, C.E., "On the Theory of Segmented Electromechanical Systems," J. Acoust. Soc. Am., Vol. 36, No. 7, pp. 1366-1370 (1964).

13. Mccammon, D.F., "The Design of Tonpiltz Piezoelectric Transducers Using Nonlinear Goal Programming," J. Acoust. Soc. Am., Vol. 68, No. 3, pp. $754-757$ (1980).

14. National-Arnold Magnetics User's Manual: Designing with Tape Wound Cores, National-Arnold Magnetics Co., Adelanto, CA (1995).

15. Stansfield, D., Underwater Electroacoustic Transducers, Bath University Press and Institute of Acoustics, Bath BA2 7AY, UK, pp. 26-30 (1990).

16. Urick, R.J., Principles of Underwater Sound, 3rd Edition McGraw-hill, New York, pp. 46-52 (1993).

17. Wilson, W.J., Encyclopedia of Applied Physics, Vol. 2, Transducer, Underwater Acoustics Chapter, Wiely-VCH Verlag GmbH, New York, USA (1998). 